\title{
Appropriateness of hysterectomy for various indications
}

\author{
Surabhi A. Bajpai* \\ Department of Obstetrics and Gynecology, Indira Gandhi Government Medical College, Nagpur, Maharashtra, India
}

Received: 27 February 2017

Accepted: 31 March 2017

\section{*Correspondence:}

Dr. Surabhi A. Bajpai,

E-mail: surabhi.bajpai@yahoo.co.in

Copyright: $\odot$ the author(s), publisher and licensee Medip Academy. This is an open-access article distributed under the terms of the Creative Commons Attribution Non-Commercial License, which permits unrestricted non-commercial use, distribution, and reproduction in any medium, provided the original work is properly cited.

\begin{abstract}
Background: To study appropriateness of hysterectomy for various indications by evaluating the referred cases for hysterectomy as per standard norms and calculating number of hysterectomies which were not indicated.

Methods: A prospective study consist of analysis of 110 cases which were advised hysterectomies in different hospitals due to various indications and number of cases who were managed conservatively in these 110 cases and did not required hysterectomy ultimately.

Results: There was significant difference in number of cases who were advised hysterectomies and number of cases who actually needed a hysterectomy. Most of cases were advised hysterectomy just on the basis of patient's complaints with no consideration to age, parity and without proper evaluation as per standard norms.

Conclusions: It was found that only $27.27 \%$ of cases who were advised hysterectomies actually needed hysterectomy for indications like symptomatic fibroid, severe dysplasia, resistant cases of AUB and intractable pain due to adenomyosis and $72.73 \%$ of cases were managed conservatively and indications for which hysterectomy was advised in such cases were inappropriate.
\end{abstract}

Keywords: Adenomyosis, Hysterectomy, Prospective study, Severe dysplasia, Symptomatic fibroid

\section{INTRODUCTION}

Hysterectomy is commonest gynaecological operation done in females however proceeding for hysterectomy patient has to be evaluated properly as regard to cause of disease and to select proper method of treatment. ${ }^{1}$ Patient should be evaluated on basis of history physical examination and discussion with the patient to match the surgical procedure to the patient in order to obtain the most satisfactory outcome so that it is not overused.

Several studies suggested that physicians might use surgical procedures inappropriately, with some patients not receiving necessary care and others exposed to unwarranted risk. ${ }^{2,3}$ To improve the quality of patient care, there has been a concerted effort to develop guidelines and other criteria for physician practice. ${ }^{4} \mathrm{An}$ equivalent effort to implement and disseminate those guidelines has been lacking. ${ }^{4}$ Hysterectomy has a wide range of indications which may not be amenable to confirmation by the pathologic examination of the specimen. ${ }^{5,6}$ New technologies are emerging for evaluation and screening for various pathologies and also conservative surgical management of various gynaecological problems. $^{7}$ This guideline presents considerations involved in decision making process of choosing hysterectomy or alternative therapies for each of the more common indications. ${ }^{7}$ The decision to proceed to a hysterectomy rests with the woman who has been fully educated to the risks and expected benefits of procedure. ${ }^{7}$ There should be careful preoperative assessment and discussion of other treatment choices. ${ }^{7}$ The American college of Obstetricians and Gynaecologist has recognised the potential for overuse and issue guidelines regarding the appropriate indications of hysterectomy. ${ }^{8}$ Appropriateness was defined to meet the expected health benefit (i.e. increase life expectancy, relief of pain, reduction in anxiety, improved functional capacity) exceeded the negative consequences (mortality, 
morbidity, pain produced from procedure, time lost from work). ${ }^{9}$

\section{METHODS}

A Prospective hospital based study of 110 cases was performed in department of obstetrics and gynaecology at a tertiary care centre in Marathwada region attending gynaecological OPD which either presented self or referred from various hospitals for hysterectomy for a duration of 18 months. They were evaluated on basis of detail history of patient regarding their complaints, obstetric history, menstrual history, clinical examination including per abdomen palpation, per speculum examination, per vaginum examination, special investigations like pap smear and ultrasonography. Criteria for assessing the cases were age, parity, diagnosis/symptoms documented by hospitals, method of evaluation as per standard norms for that particular gynaecological conditions and prevention of hysterectomy whenever possible.

\section{Inclusion criteria}

All patients suffering from gynaecological problem advised hysterectomy by various hospitals.

\section{Exclusion criteria}

All patients suffering from malignant gynaecological conditions.

\section{RESULTS}

There was significant difference in number of cases who were advised hysterectomies and number of cases who actually needed a hysterectomy. Most of cases were advised hysterectomy just on the basis of complaints with no consideration to their age, parity and without proper evaluation as per standard norms.

Age group most commonly advised hysterectomy is between 31 years- 41 years but $6.36 \%$ of cases were under 30 years which were advised hysterectomy out of which only 1 case actually needed hysterectomy (Table 1 ).

Table 1: Age wise distributions of patients advised hysterectomy.

\begin{tabular}{|lll|}
\hline Age group & No. of cases & $\%$ \\
\hline$<30$ & 7 & 6.38 \\
\hline $31-40$ & 55 & 50 \\
\hline $41-50$ & 42 & 38.18 \\
\hline $51-60$ & 6 & 5.45 \\
\hline
\end{tabular}

Multipara were most commonly advised hysterectomy however 1 case of nullipara and 10 cases of primipara's were advised hysterectomy (Table 2).
Table 2: Shows parity of the patient to which hysterectomy was advised.

\begin{tabular}{|lll|}
\hline Parity & No. of cases & $\%$ \\
\hline Nulligravida & 1 & 0.09 \\
\hline Primipara & 10 & 9.09 \\
\hline Multipara & 95 & 86.36 \\
\hline Grandmultipara & 4 & 3.63 \\
\hline
\end{tabular}

In 21 cases, just on basis of complaints like bleeding, white discharge, pain during menstruation, pain in abdomen were advised hysterectomies and 89 cases on the basis of diagnosis (Table 3).

Table 3: Shows various complaints on the basis of which hysterectomy was advised.

\begin{tabular}{|lll|}
\hline Complaints & No. of cases & $\%$ \\
\hline Bleeding & 11 & 10 \\
\hline White Discharge & 4 & 3.63 \\
\hline Pain during menstruation & 1 & 0.09 \\
\hline Pain in abdomen & 5 & 4.54 \\
\hline Rest on basis of diagnosis & 89 & 80.90 \\
\hline
\end{tabular}

AUB was the most common indication for which hysterectomy was advised followed by chronic pelvic pain (Table 4).

Table 4: Shows various indications for which hysterectomy was advised.

\begin{tabular}{|lll|}
\hline Indications & No. of cases & $\%$ \\
\hline AUB & 63 & 57.2 \\
\hline Chronic pain & 18 & 16.3 \\
\hline Adenomyosis & 9 & 8.1 \\
\hline Chronic cervicitis & 4 & 3.6 \\
\hline Dysplasia of cervix & 3 & 2.7 \\
\hline Fibroid uterus & 12 & 10.9 \\
\hline Polyp & 1 & 0.9 \\
\hline
\end{tabular}

Table 5: Shows how many cases advised hysterectomy were managed medically and how many with minor surgery and ultimately how many required hysterectomy.

\begin{tabular}{|lcc|}
\hline Management & No of cases & $\%$ \\
\hline Medically & 41 & 37.27 \\
\hline $\begin{array}{l}\text { Minor surgery (D and C, } \\
\text { diagnostic laparoscopy, } \\
\text { cryocautery, cervix biopsy) }\end{array}$ & 39 & 35.45 \\
\hline Hysterectomy & 30 & 27.27 \\
\hline
\end{tabular}

Table 6: Shows appropriateness of hysterectomy as per indication.

\begin{tabular}{|lll|}
\hline A ppropriateness & No of cases & $\%$ \\
\hline Appropriate & 30 & 27.27 \\
\hline Inappropriate & 80 & 72.73 \\
\hline
\end{tabular}


Out of 110 cases which were advised hysterectomy only in 30 of the cases hysterectomy was actually done and 41 cases were managed on medical treatment and 39 cases with minor procedures like $\mathrm{D}$ and $\mathrm{C}$, diagnostic laparoscopy, cryocautery (Table 5). Hysterectomy was appropriate in 30 cases and inappropriate in 80 cases (Table 6). The appropriateness of hysterectomy for various indication. (Table 7).

Table 7: Shows appropriateness of hysterectomy for various indication.

\begin{tabular}{|llllll|}
\hline Indications & No. of cases & Appropriate & \multicolumn{3}{c|}{ Inappropriate } \\
\hline AUB & 63 & No. & $\mathbf{\%}$ & No. & \% \\
\hline Chronic pain & 18 & 20 & 31.7 & 43 & 68.2 \\
\hline Adenomyosis & 9 & 4 & 20.0 & 14 & 77.70 \\
\hline Chronic cervicitis & 4 & 2 & 22.2 & 7 & 77.70 \\
\hline Cervical dysplasia & 3 & 0 & 0 & 4 & $100.0 \%$ \\
\hline Fibroid uterus & 12 & 1 & 33.3 & 2 & 66.60 \\
\hline Polyp & 1 & 3 & 25 & 9 & 75.00 \\
\hline
\end{tabular}

\section{DISCUSSION}

After reviewing 110 cases referred or came as self for hysterectomy advised by various hospitals in present study, it is observed that hysterectomies were advised with writing only symptoms of patients like white discharge per vaginum, bleeding per vaginum without mentioning clinical diagnosis or not even evaluating patients with a basic screening procedure like pap smear. Kowdipally mandal of medak district in 2005 and field study conducted by life HRG 2013 conducted on 171 affected women in municipal mandal indicates significant rise in hysterectomy below 30 years of age between $34.89 \%$ in 2005 to $59.74 \%$ in 2011 in just a period of 6 years. ${ }^{10}$

S. J. Bernstein in study of appropriation of hysterectomy mentioned over 5 lakh hysterectomies performed each year in USA and among these many hysterectomies may be unnecessary and overuse of hysterectomy. ${ }^{9}$

Mitchell S Broder et al in study of appropriateness of recommendations of hysterectomy concluded hysterectomy is often recommended for indications judged inappropriate. ${ }^{4}$ Patient and physician should work together to ensure that proper diagnostic evaluation has to be done and appropriate treatment is considered before hysterectomy is recommended. ${ }^{7}$

\section{CONCLUSION}

$77.2 \%$ of total cases of chronic pain were unnecessary advised hysterectomy in our present study whereas in Broder $49 \%$ had undergone unnecessary hysterectomy. $66.6 \%$ of cases of cervical dysplasia were unnecessary advised hysterectomy in our present study and $45 \%$ had undergone unnecessary hysterectomy in Broder. For fibroid uterus $75 \%$ hysterectomies in our study was inappropriate and $79 \%$ had undergone hysterectomy inappropriately in Broder. Broder out of 497 hysterectomies performed $367(70 \%)$ of hysterectomies did not meet the level of care recommended by the expert panel and were judged to be recommended inappropriately.

\section{Funding: No funding sources \\ Conflict of interest: None declared}

Ethical approval: The study was approved by the Institutional Ethics Committee

\section{REFERENCES}

1. Statistics Canada, Surgical procedures and treatments. 1992-1993;82-217:32-33.

2. McGlynn EA, Naylor CD, Anderson GM, Leape LL, Parke RE, Hilborne LH, et al. Comparison of the appropriateness of coronary angiography and coronary artery bypass graft surgery between Canada and New York State. JAMA. 1994;272:934-40.

3. Bernstein SJ, Hilborne LH, Leape LL, Park RE, Brook RH. The appropriateness of use of cardiovascular procedures in women and men. Arch Intern Med. 1994;154:2759-65.

4. Broder MS, Kanouse DE, Mittman BS, Bernstein SJ. The appropriateness of recommendations for hysterectomy. Obstetrics and Gynecology. $2000 \mathrm{Feb}$ 29;95(2):199-205.

5. Bachman GA. Hysterectomy: a critical review. J Reprod Med. 1990;35(9):839-62.

6. Lee N, Dicker R, Rubin G, Ory H. Confirmation of the pre-operative diagnosis for hysterectomy. Am J Obstet Gynecol. 1984;150:283-7.

7. SOGC clinical Practice guidelines. 2002;1-12.

8. American College of Obstetricians and Gynaecologists task force on quality assurance. Quality assurance in Obstetrics and Gynaecology. Washington, DC: American College of Obstetricians and Gynaecologists; 1989.

9. Bernstein SJ, McGlynn EA, Siu AL, Roth CP, Sherwood MJ, Keesey JW, et al. The appropriateness of hysterectomy: a comparison of care in seven health plans. Jama. 1993;269(18):2398-402. 
10. Mamidi BB. International journal of social work and human services practice. 2013;1(1):64-75.
Cite this article as: Bajpai SA. Appropriateness of hysterectomy for various indications. Int J Reprod Contracept Obstet Gynecol 2017;6:1956-9. 